\title{
Nefroblastoma quístico parcialmente diferenciado. Reporte de caso
}

\author{
Cystic partially differentiated nephroblastoma. Case report \\ Reyner Loza Munarriz ${ }^{1, a}$, Angelica Ynguil Muñoz ${ }^{1, a}$, Jenny Ponce Gambini ${ }^{1, a}$, \\ Giannina A. Álvarez Yupanqui ${ }^{1, a}$, Jaime Cok García ${ }^{2, b}$, Raúl Medina Ninacondor ${ }^{3, c}$, Luis Zegarra Montes ${ }^{3, c}$
}

\section{RESUMEN}

El nefroblastoma quístico parcialmente diferenciado, es una variante de tumor de Wilms, de presentación muy poco común, es quístico totalmente multilocular con tabicaciones finas que muestran en su interior cúmulos de elementos de blastema o epiteliales en diferenciación. Se manifiesta principalmente en menores de dos años. Se presenta el caso de un varón de 6 meses que desarrolló una tumoración renal derecha. Los hallazgos histopatológicos de la pieza extirpada por nefrectomía fueron: presentación de formaciones quísticas, con septos fibrovasculares que muestran tejido renal primitivo con presencia de túbulos y glomérulos en diferenciación sin efecto de masa. El diagnóstico final fue de nefroblastoma quístico parcialmente diferenciado. La evolución del paciente fue favorable.

PALABRAS CLAVE: Tumor de Wilms, quistes, enfermedades renales quísticas. (Fuente: DeCS BIREME).

\section{SUMMARY}

Cystic partially differentiated nephroblastoma is a clinical variant presentation of Wilms tumor. It is very uncommon and it is composed of multiloculated cysts with fine trabecula containing epithelial cells in process of differentiation. It usually affects children below 2 years of age. We present the case of a 6-month male patient who presented with a right renal tumor. Pathological findings of the resected kidney showed cystic lesions with multiple fibro vascular septum that contained primitive tubular and glomerular kidney cells with no mass effect. The final diagnosis was cystic partially differentiated nephroblastoma. The clinical evolution was favorable.

KEYWORDS: Wilms Tumor, cysts, kidney diseases, cystic. (Source: MeSH BIREME).

\section{INTRODUCCIÓN}

El nefroblastoma quístico parcialmente diferenciado (NQPD) es una lesión tumoral quística multilocular del riñón que se caracteriza por un comportamiento bimodal y de curso clínico benigno, hay dos picos de edad en los que se presenta, niños menores de dos años con predominancia en varones $\mathrm{y}$ es extremadamente raro en adultos de edad media o mayores con aumento de prevalencia en mujeres (1).

Existe cierto debate acerca de si estas lesiones pertenecen a una parte del espectro de enfermedades con una etiología común (2).

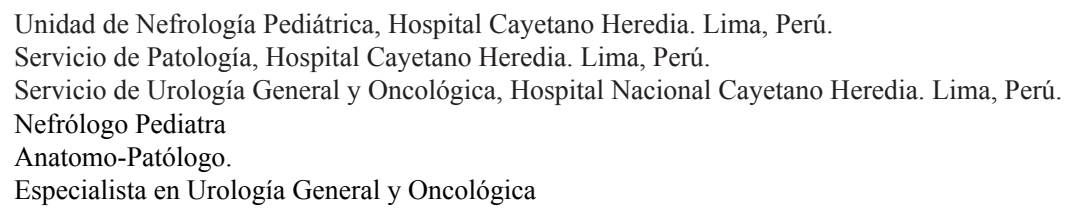


Muchos casos son asintomáticos y pueden presentarse como tumoración o hematuria, debe diferenciarse de entidades quísticas renales malignas, por lo que la histopatología es la que determina el diagnostico final (3).

El tratamiento estándar es quirúrgico, Los pacientes con enfermedad en estadio I tienen una tasa de supervivencia del 100\% con cirugía (4).

Se presenta el caso de un lactante de seis meses con la presencia de masa tumoral en abdomen de progresión rápida y, nunca descrito en nuestro país.

\section{PRESENTACIÓN DEL CASO}

Lactante varón de 6 meses de edad, con antecedente de prematuridad, durante su evaluación por consultorio externa a los cuatro meses la madre refirió aumento progresivo del abdomen. Al examen clínico se encontró una tumoración abdominal renal palpable; debido a esto se indicó hospitalización por diagnóstico presuntivo de displasia renal multiquistica derecha versus tumor de Wilms y se indicó exploración quirúrgica. En la tomografía abdominal computarizada (TAC) se evidenció masa abdominal multiquistica dependiente de riñón derecho, que ocupaba dos tercios de abdomen (Figura 1).

Durante su hospitalización cursó con niveles de presión arterial por encima del percentil 95 recibiendo captopril, nifedipino y carvedilol. Ingresó a sala de operaciones y se realizó nefrectomía derecha, se extrajo un riñón de aproximadamente 1400 gramos de 22x15x6cm (Figura 2).

En el postoperatorio requirió soporte inotrópico por hipotensión, luego cursó con hipertensión arterial por

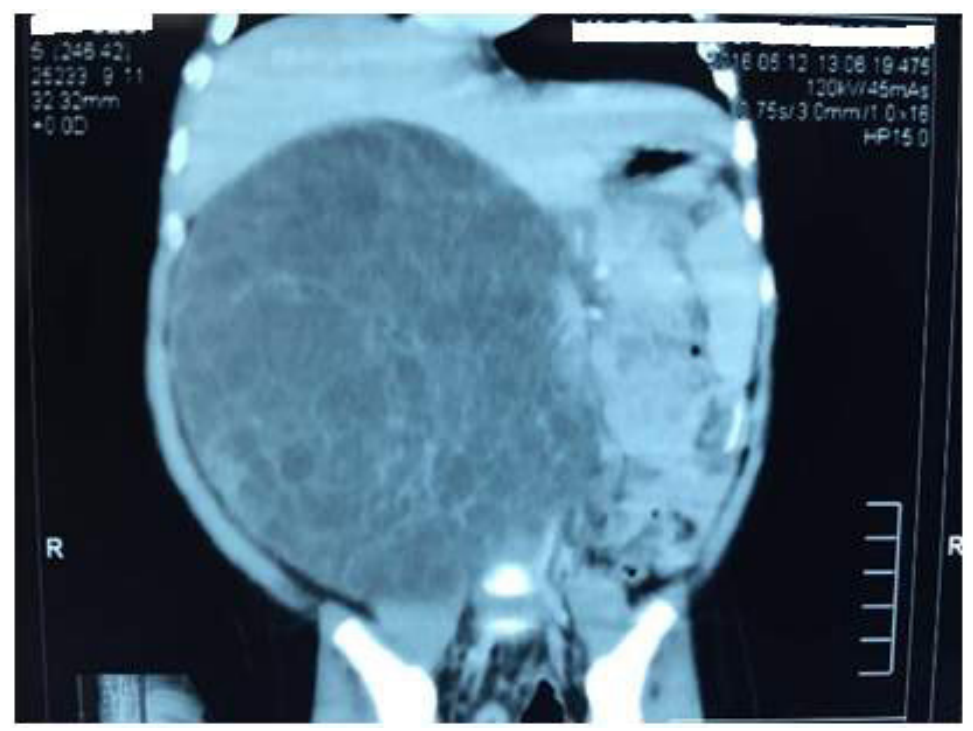

Figura 1. TAC abdominal con gran tumoración dependiente de riñón.
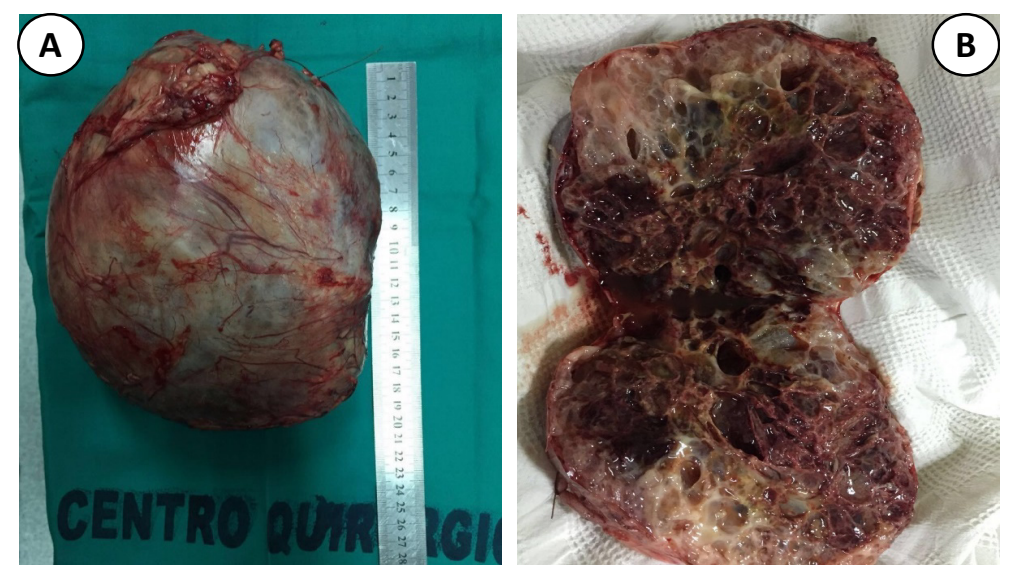

Figura 2. A: Gran tumoración renal derecha. B: Al corte se aprecia tumor multiquístico. 


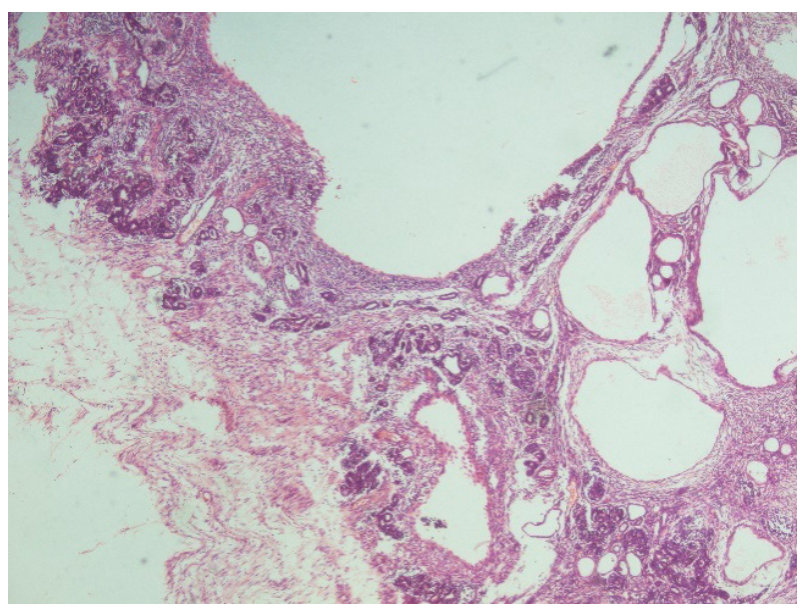

Figura 3. La formación quística multiloculada muestra elementos epiteliales en diferenciación, sin efecto de masa, dentro de las tabicaciones del tumor, no deforman el tabique que está recubierto por monocapa de epitelio plano o cuboideo (HE 40X).

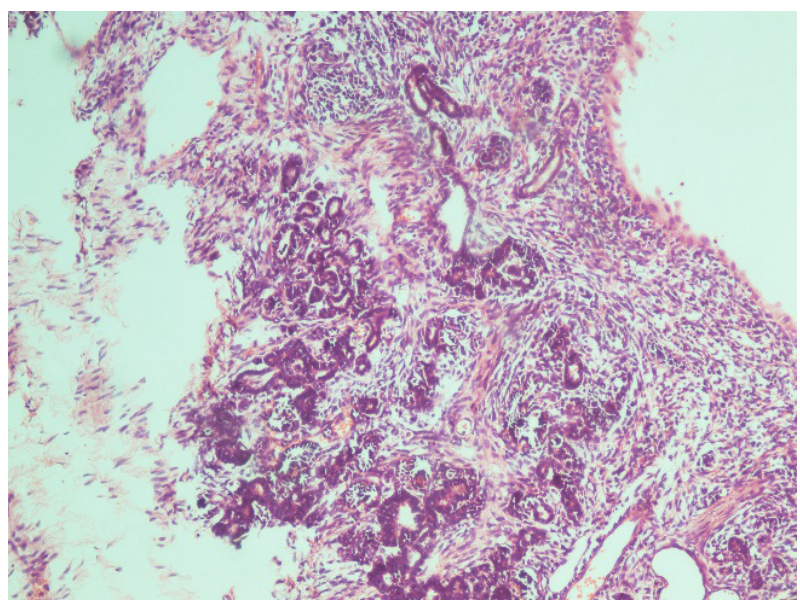

Figura 4. Nidos de elementos epiteliales en diferenciación que no alteran el perfil liso del tabique (HE 100X).

lo que hubo necesidad de tratamiento antihipertensivo con calcio antagonista. Al quinto día post operatorio cursó con proceso febril de origen respiratorio por lo que se solicitaron reactantes de fase aguda, los que fueron negativos.

El resultado del estudio histopatológico fue neuroblastoma quístico parcialmente diferenciado, con presencia de formaciones quísticas, los septos fibrovasculares con tejido renal primitivo con túbulos y glomérulos en diferenciación sin efecto de masa que deforme el tabique (Figuras 3 y 4 ).

La evolución fue favorable con caída de la fiebre, control de presión arterial con disminución de antihipertensivos, flujos urinarios adecuados $\mathrm{y}$ pruebas de función renal dentro de límites normales. El paciente fue dado de alta en buena condición clínica y actualmente se encuentra estable, en seguimiento ambulatorio.

\section{DISCUSIÓN}

Las neoplasias renales con quistes dominantes representan un amplio espectro que incluyen el Nefroblastoma quístico parcialmente diferenciado, el tumor estromal y epitelial, sarcoma sinovial y el cáncer renal quístico multilocular (1).

La terminología es muy variada. Éstos son algunos de los sinónimos del nefroblastoma quístico parcialmente diferenciado o multiquístico referidos en la literatura médica: "tumor renal multilocular", "nefroma quístico benigno multilocular", "quiste multilocular", "nefroblastoma poliquístico", "nefrona quística", "tumor de Wilms poliquístico bien diferenciado", "tumor de Perlman", "nefroblastoma diferenciado" (1).

El nefroblastoma quístico es una neoplasia renal benigna y rara con buen pronóstico que no se transmite de forma genética, son usualmente unilaterales, la patogenia no ha sido aclarada, para algunos autores esta sería una lesión primariamente tumoral, para otros sería una anomalía del desarrollo o una combinación entre elementos neoplásicos y disgenéticos $(2,3)$.

Puede presentar signos que incluyen tumoración abdominal, dolor y hematuria, pero la mayoría de los casos de nefroblastoma quístico se encuentran incidentalmente, lo más común es la masa abdominal asintomática como hallazgo, ocasionalmente se asocian a hipertensión, los exámenes de laboratorio generalmente son normales, y radiológicamente, la mayoría son solitarios, localizados centralmente y de tamaño variable y comúnmente muestran calcificaciones (4).

Están formados por múltiples quistes no comunicados, macroscópicamente pueden presentar hemorragia y necrosis, con cavidades de tamaños variables y separadas por septos fibrosos sin masas o nódulos expansivos. En la microscopía se evidencia cavidades quísticas revestidas por epitelio cúbico simple que puede estar aplanado por compresión, su citoplasma es eosinofílico y sus núcleos no muestran atipia. Los septos están formados por tejido fibroso y contienen nidos de blastema, sin formar masas sólidas expansivas $(5,6)$. 
El tratamiento para cualquier lesión quística multilocular, incluso para las variantes más benignas, es la nefrectomía. Si la lesión está localizada y hay tejido normal preservado, la escisión de la lesión o la nefrectomía parcial es posible (7).

En nuestro de caso la edad de presentación, la forma clínica y de laboratorio y anatomía patológica y pronóstico coincide con los hallazgos de la literatura.

\section{Declaración de Financiamiento y de conflictos de intereses:}

Los autores declaran no tener conflictos de intereses.

\section{Contribución de autoría:}

RLM，AYM，JPG，GAAY，JCG，RMN，LZM: Descripción y discusión del caso; redacción del artículo

\section{Correspondencia:}

Reyner Loza Munarriz

Correo electrónico: reyner.loza@upch.pe

\section{REFERENCIAS BIBLIOGRÄFICAS}

1. Bernal M, Castillo C, Kakarieka E, Las Heras J. Nefroblastoma quístico parcialmente diferenciado. Rev chil pediatr. 1991; 62(2):124-127.

2. Subirá J, Sánchez J, Elizalde A, et al. Nefroma quístico multilocular: Aportación de 3 nuevos casos. Arch Esp Urol. 2009; 62(1):62-66.

3. Boybeyi O, Karnak I, Orhan D, et al. Cystic nephroma and localized renal cystic disease in children: diagnostic clues and Management. J Pediatr Surg. 2008; 43(11):985-9.

4. Luithle T, Szavay P, Furtwängler R, Graf N, Fuchs J; SIOP/GPOH Study Group. Treatment of cystic nephroma and cystic partially differentiated nephroblastoma--a report from the SIOP/GPOH study group. J Urol. 2007; 177(1):294-6.

5. van den Hoek J, de Krijger R, van de Ven K, Lequin M, van den Heuvel-Eibrink MM. Cystic nephroma, cystic partially differentiated nephroblastoma and cystic Wilms' tumor in children: a spectrum with therapeutic dilemmas. Urol Int. 2009; 82(1):65-70.

6. Blakely ML, Shamberger RC, Norkool P, et al. Outcome of children with cystic partially differentiated nephroblastoma treated with or without chemotherapy. J Pediatr Surg. 2003; 38 (6):897-900.

7. Cajaiba MM, Khanna G, Smith EA, et al. Pediatric cystic nephromas: distinctive features and frequent DICER1 mutations. Hum Pathol. 2016; 48:81-7.

Recibido: 04/08/2017

Aceptado: 21/09/2017 